Article

\title{
$\beta$-Cyclodextrin Derivative Grafted on Silica Gel Represents a New Polymeric Sorbent for Extracting Nitisinone from Model Physiological Fluids
}

\author{
Magdalena Danek ${ }^{1, *}$, Anna Korytkowska-Wałach ${ }^{2}$ and Hanna Barchańska ${ }^{1}$ \\ 1 Department of Inorganic Chemistry, Analytical Chemistry and Electrochemistry, Faculty of Chemistry, \\ Silesian University of Technology, B. Krzywoustego 6 St., 44-100 Gliwice, Poland; Hanna.Barchanska@polsl.pl \\ 2 Department of Organic Chemistry, Bioorganic Chemistry and Biotechnology, Faculty of Chemistry, \\ Silesian University of Technology, B. Krzywoustego 4 St., 44-100 Gliwice, Poland; \\ Anna.Korytkowska-Walach@polsl.pl \\ * Correspondence: Magdalena.Danek@polsl.pl
}

\section{check for}

updates

Citation: Danek, M.;

Korytkowska-Wałach, A.; Barchańska,

H. $\beta$-Cyclodextrin Derivative Grafted

on Silica Gel Represents a New

Polymeric Sorbent for Extracting

Nitisinone from Model Physiological

Fluids. Molecules 2021, 26, 5945.

https://doi.org/10.3390/

molecules26195945

Academic Editors: Eric Guibal and

Chiara Bisio

Received: 27 August 2021

Accepted: 27 September 2021

Published: 30 September 2021

Publisher's Note: MDPI stays neutral with regard to jurisdictional claims in published maps and institutional affiliations.

Copyright: (c) 2021 by the authors. Licensee MDPI, Basel, Switzerland. This article is an open access article distributed under the terms and conditions of the Creative Commons Attribution (CC BY) license (https:/ / creativecommons.org/licenses/by/ $4.0 /)$.

\begin{abstract}
Nitisinone (NTBC) is used in the treatment of disorders affecting the tyrosine pathway, including hereditary tyrosinemia type I, alkaptonuria, and neuroblastoma. An inappropriate dosage of this therapeutic drug causes side effects; therefore, it is necessary to develop a rapid and sensitive method to monitor the content of NTBC in patients' blood. This study aimed to develop anew polymeric sorbent containing $\beta$-cyclodextrin $(\beta-C D)$ derivatives grafted on silica gel to effectively extract NTBC from model physiological fluids. The inclusion complex formed between $\beta-C D$ and NTBC was examined by proton nuclear magnetic resonance spectroscopy. The novel sorbents with derivatives of $\beta$-CD were prepared on modified silica gel using styrene as a comonomer, ethylene glycol dimethacrylate as a crosslinking agent, and 2,2'-azo-bis-isobutyronitrile as a polymerization initiator. The obtained products were characterized via Fourier transform infrared spectroscopy and then used as sorbents as part of a solid phase extraction technique. High NTBC recovery (70\%indicated that the developed polymeric sorbent may be suitable for extracting this compound from patients' blood samples.
\end{abstract}

Keywords: nitisinone; $\beta$-cyclodextrin; nuclear magnetic resonance; Fourier transform infrared spectroscopy; model physiological fluids; solid phase extraction; liquid chromatography

\section{Introduction}

Nitisinone (2-(2-nitro-4-trifluoromethylbenzoyl)cyclohexane-1,3-dione; NTBC) represents a functional triketone compound. Toxicology tests of NTBC involving rats have shown that it is an inhibitor of the enzyme, hydroxyphenylpyruvate dioxygenase (HPPD), which participates in tyrosine metabolism. This discovery inspired further research into the potential implementation of this compound as a drug for treating various disorders affecting the tyrosine pathway [1-3].

NTBC was approved for use as a drug by the United States Food and Drug Administration and the European Union Drug Agency in 2002 and 2005, respectively [4,5]. This drug is marketed as Orfadin ${ }^{\circledR}$ and is used in the treatment of hereditary tyrosinemia type I (HT1), which is a rare inborn metabolic disorder that is characterized by a deficiency of fumarylacetoacetate during the metabolism of tyrosine; this leads to an increase in the concentration of this amino acid and other compounds that can be toxic for humans. The application of NTBC reduces the production of toxic metabolites by effectively blocking the tyrosine metabolic pathway [4-7]. NTBC can be also used in the treatment of alkaptonuria [8,9] or neuroblastoma [4,10].

Patients undergoing an NTBC treatment process may experience side effects; therefore, it is crucial to select the safest and most appropriate therapeutic dose. To do so, it is 
necessary to employ a quick and sensitive method, which involves continuously monitoring the patient's metabolism, controlling the concentration of NTBC in physiological fluids, and appropriately adjusting the drug dose $[8,11,12]$.

The elaboration of an analytical method requires several key steps, including sampling, pretreatment, transport, storage, sample preparation, final analysis, and analytical data processing. However, the most important step in this approach is the sample preparation because it has a significant impact on the results of the final analysis. This step may involve various extraction techniques, which enable: (i) the extraction of the analyte(s); (ii) preconcentration; and (iii) purification of the sample [13-17].

Statistics indicate that the most commonly used extraction technique in analytical chemistry is solid phase extraction (SPE) [18]. The SPE procedure involves conditioning the sorbent, loading the sample, removing any interfering (matrix) compounds, and eluting the analyte [13]. Selecting an appropriate sorbent according to the physicochemical properties of the analyte and matrix compounds allows for high recovery of the desired analyte and effective clean-up of the sample. Sorbents used in SPE generally belong to three groups: inorganic oxides (e.g., silica gel), low-specificity sorbents (e.g., octadecyl sorbent, C18; polymeric sorbent styrene-divinylbenzene, HLB), and specific sorbents (e.g., molecularly imprinted polymers, MIPs) [19-21].

Recently, there has been increased interest regarding the application of polymeric sorbents based on cyclodextrin (CD) [22-25]. CDs are cyclic oligosaccharides that can be obtained via the enzymatic degradation of starch. Moreover, they are low-cost natural materials that do not pose a risk to the environment $[25,26]$. In general, CDs are composed of six or more D-glucopyranoside units linked via $\alpha(1-4)$; native CDs contain six $(\alpha-C D)$, seven $(\beta-C D)$, or eight $(\gamma-C D)$ units of glucose. The most frequently used $C D$ is $\beta-C D$ owing to its cost-effectiveness, wide availability, and capacity to form inclusion compounds with various substances through host-guest interactions. The central portion of $\beta-C D$ contains seven units of glucose and exhibits hydrophobic properties, whereas the external part includes hydroxyl groups and is hydrophilic. This unique structure allows facile encapsulation of various compounds, and modifications of the $\beta-C D$ surface can expand its ability to encapsulate compounds characterized by diverse physicochemical properties [26]. Moreover, the bonding of the $\beta-C D$ to the support material (e.g., silica gel) increases the adsorption properties of the polymeric sorbents based on CD [27-30].

To develop new sorbents, it is necessary to estimate the interactions between the host (e.g., functional monomer) and guest (e.g., analyte); such evaluations are typically carried out using proton nuclear magnetic resonance spectroscopy $\left({ }^{1} \mathrm{H}-\mathrm{NMR}\right)$, which can provide key information about the host-guest interaction. This capability originates from the fact that the formation of a host-guest complex induces changes in the electron densities within the functional monomer and the analyte, which leads to observable changes in the proton chemical shifts [31,32].

A comprehensive literature review revealed that dried blood spot (DBS) testing is the sole technique used to determine the NTBC concentration in patient blood samples [12,33-36]. Therefore, it is necessary to find new analytical methods to provide an alternative to DBS.

The present study aimed to develop a new polymeric sorbent containing a derivative of $\beta$-CD grafted on silica gel for the extraction of NTBC from model physiological fluids. The interactions between $\beta-\mathrm{CD}$ and NTBC were evaluated using ${ }^{1} \mathrm{H}-\mathrm{NMR}$, and the obtained sorbent was characterized by Fourier transform infrared spectroscopy (FTIR). The applied analytical method based on SPE with the new polymeric sorbent was validated. Overall, the results presented herein indicate that the developed sorbent can be used to effectively extract NTBC from patient blood samples. 


\section{Results and Discussion}

\subsection{Characterization of $\beta-C D / N T B C$ Complexes by NMR}

An aqueous solution of 3-(trimethylsilyl)propionic-2,2,3,3- $\mathrm{d}_{4}$ acid sodium salt (TSP) was used as an external reference to avoid errors in the determination of association constants [37].

\subsubsection{Continuous Variation Method for Determining Stoichiometry}

First, the NMR characterization of the NTBC / $\beta$-CD complexation involved determining the stoichiometry of the formed complex.

Using a continuous variation method, the stoichiometry of the generated complex was determined. The Job's plots (Figure 1) constructed based on the chemical shifts of corresponding protons are both characterized by a sharp symmetrical shape, with a maximum at mole fraction of nitisinone $\mathrm{xNTBC}=0.5$, which corresponds to $1: 1$ stoichiometry of the complex formed.

a)

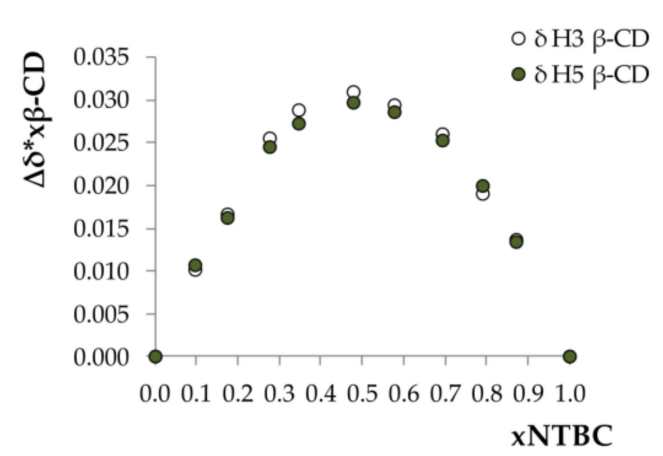

b)

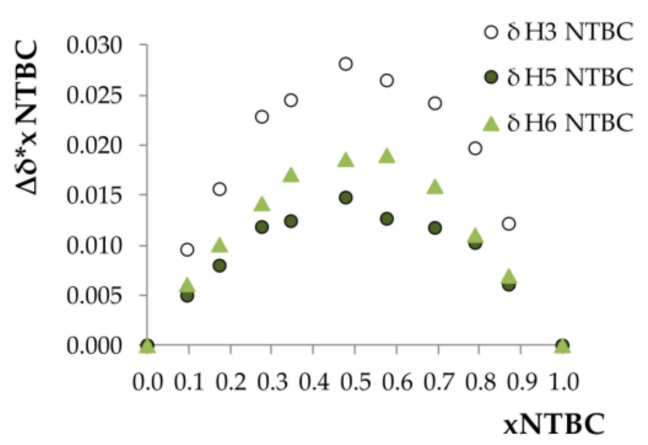

Figure 1. Job's plots for $\beta-\mathrm{CD} / \mathrm{NTBC}$ constructed according to the chemical shifts of (a) protons $\mathrm{H}^{3}$ and $\mathrm{H}^{5}$ of $\beta-\mathrm{CD}$, and $(\mathbf{b})$ the aromatic protons of NTBC.

\subsubsection{D-ROESY}

Two-dimensional rotating-frame Overhauser effect spectroscopy (2D ROESY) was used to confirm the formation of the inclusion complex. A four-fold excess of NTBC was introduced to shift the complexation reaction toward complex formation. Figure 2 shows the correlation signals, which indicate the close proximity between $\mathrm{H}^{3}$ of $\beta-\mathrm{CD}$ and $\mathrm{H}^{6}$ of NTBC and between $\mathrm{H}^{5}$ of $\beta-C D$ and $\mathrm{H}^{5}$ of NTBC. The proposed orientation of the NTBC molecule in the cyclodextrin cavity is also presented.

\subsubsection{Titrations to Obtain Association Constants}

The association constant governing NTBC/ $\beta$-CD complex formation was determined from NMR titration experiments (i.e., measuring changes in chemical shifts as a function of the concentration of one reagent). For these experiments, the $\beta-C D$ concentration was held constant, and the concentration of NTBC was increased incrementally to cover host:guest ratios from 0.0 to 4.0. An upfield shift of the signals corresponding to the inner protons of $\beta-\mathrm{CD}$ (i.e., $\mathrm{H}^{3}$ and $\mathrm{H}^{5}$ ) was observed as the concentration of NTBC increased. The collected NMR data were fitted using a curve-fitting method within the WinEQNMR computer program (Figures 3 and 4). This program applied non-linear least-squares subroutines that carried out refinements of various parameters according to the Levenberg-Marquardt method, which does not require that one reactant exists in a large excess [38]. 


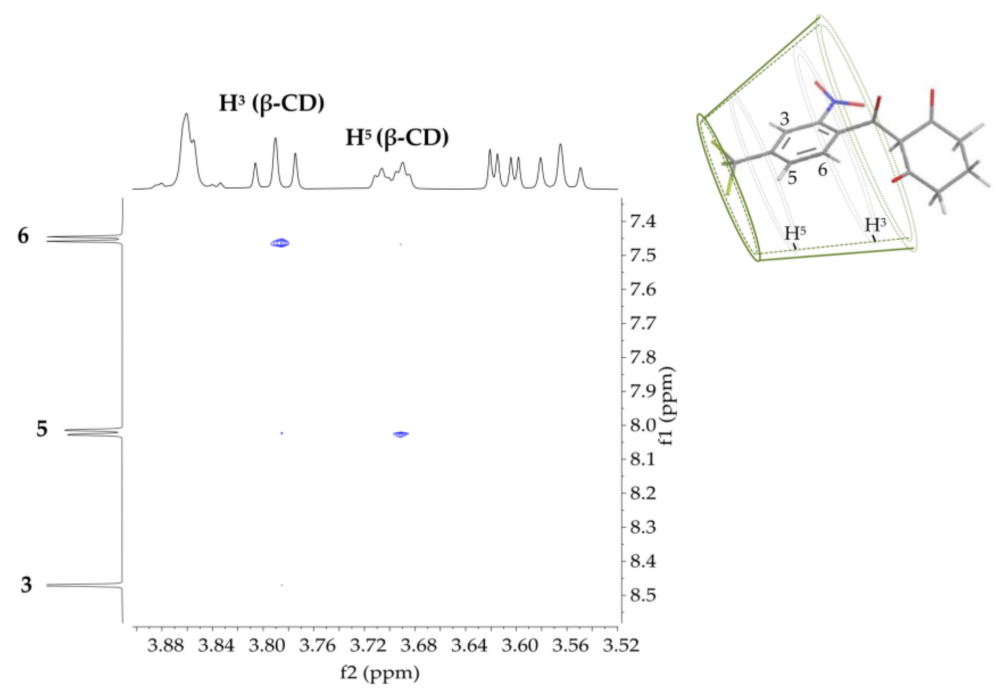

Figure 2. Proposed geometry of the $\beta-\mathrm{CD} / \mathrm{NTBC}$ inclusion complex and a partial contour plot of the 2D-ROESY spectrum recorded for a 4:1 $\beta$-CD/NTBC ratio.

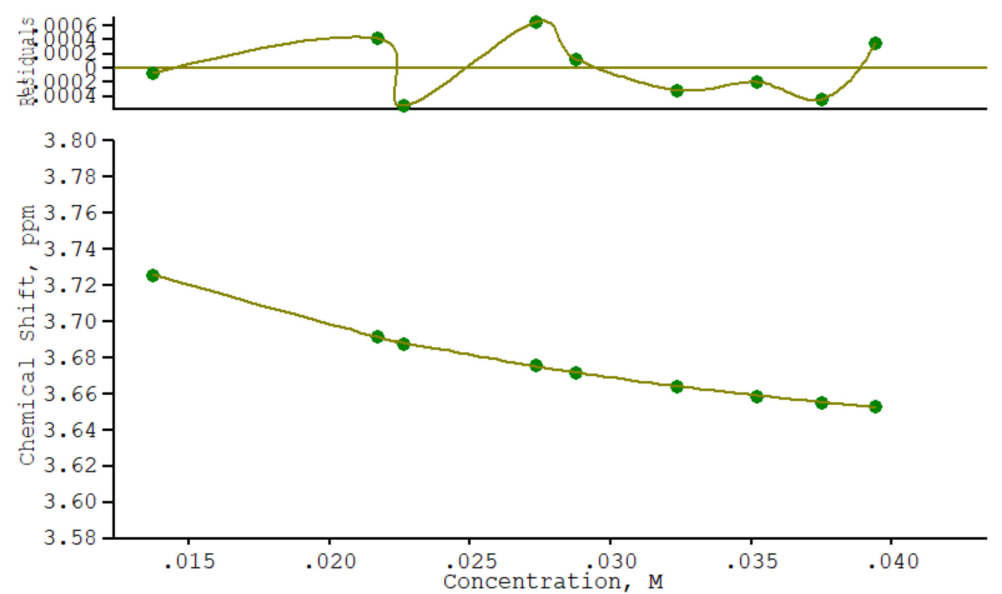

Figure 3. The chemical shift of the $\mathrm{H}^{3}$ proton of $\beta-\mathrm{CD}$ as a function of the NTBC concentration and the experimental data fitting (by WinEQNMR) for the NMR titration of $\beta-C D$ with NTBC (a magnification of the residuals is also presented).
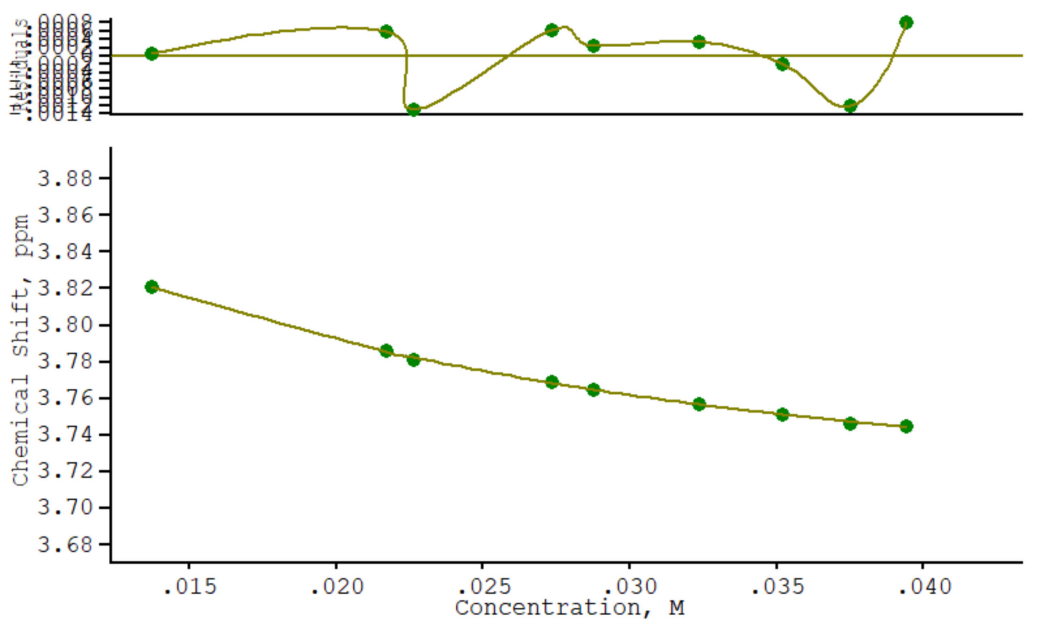

Figure 4. The chemical shift of the $\mathrm{H}^{5}$ proton of $\beta-\mathrm{CD}$ as a function of the NTBC concentration and the experimental data fitting (by WinEQNMR) for the NMR titration of $\beta-C D$ with NTBC (a magnification of the residuals is also presented). 
The calculated association constants (within the error given by WinEQNMR2) based on the chemical shifts of the $\mathrm{H}^{3}$ and $\mathrm{H}^{5}$ signals of $\beta-\mathrm{CD}$ are $85.5(8.5) \mathrm{M}^{-1}$ and $94.4(6.0) \mathrm{M}^{-1}$, respectively. Individual association constant values differ by about $10 \%$. Good agreement between the association constants $\mathrm{K}$ determined from the two $\beta-\mathrm{CD}$ signals, as well as the absence of systematic deviations in this case, confirms the assumed 1:1 intracavity complexation and that no other supramolecular species are present. The equilibrium individual association constants obtained from NMR titration corresponds to a Gibbs free energy $\Delta \mathrm{G}=-11 \mathrm{~kJ} / \mathrm{mol}$. $\Delta \mathrm{G}$ values are negative, which indicates that inclusion process proceed spontaneously at $25^{\circ} \mathrm{C}$.

The results of these NMR studies of the complexation of NTBC by $\beta-C D$ clearly confirm that inclusion complexes are formed. Therefore, it was concluded that the incorporation of $\beta$-CD molecules on the surface of the sorbent should improve its adsorption properties towards NTBC molecules.

\subsection{Preparation and Characterization of Sorbents}

A radical polymerization method was used to attach functional monomers bearing $\beta-C D$ moieties onto silica gel in order to prepare a sorbent containing surface $\beta$-CDs for the complexation of NTBC. In the first step of this process, the silica surface was prepared by introducing bonds conducive to free radical polymerization.

In this case, 3-(Trimethoxysilyl)propyl methacrylate ( $\gamma$-MAPS) containing -Si(- $\left.\mathrm{OCH}_{3}\right)_{3}$ groups, capable of reacting with hydroxyl groups of the silica surface, was used. Thus, methacrylate bonds of $\gamma$-MAPS are able for free radical polymerization with functional $\beta$-CD monomers.

The functional monomers bearing $\beta-C D$ moieties were synthesized according to a modified version of the procedure reported by Liu and Fan [39], which involved the simple addition of maleic anhydride to $\beta-C D$ (Scheme 1). By using an appropriate molar ratio of maleic anhydride to cyclodextrin and an appropriate reaction time, a functional monomer was obtained. According to ${ }^{1} \mathrm{H}-\mathrm{NMR}$ analysis, each monomer contains an average of 1.14 molecules of maleic anhydride per one molecule of CD. It was presumed that this number of maleic moieties would not reduce the tendency of $C D$ to form inclusion complexes, but rather, it ensured the incorporation of the functional monomer into the polymer network.
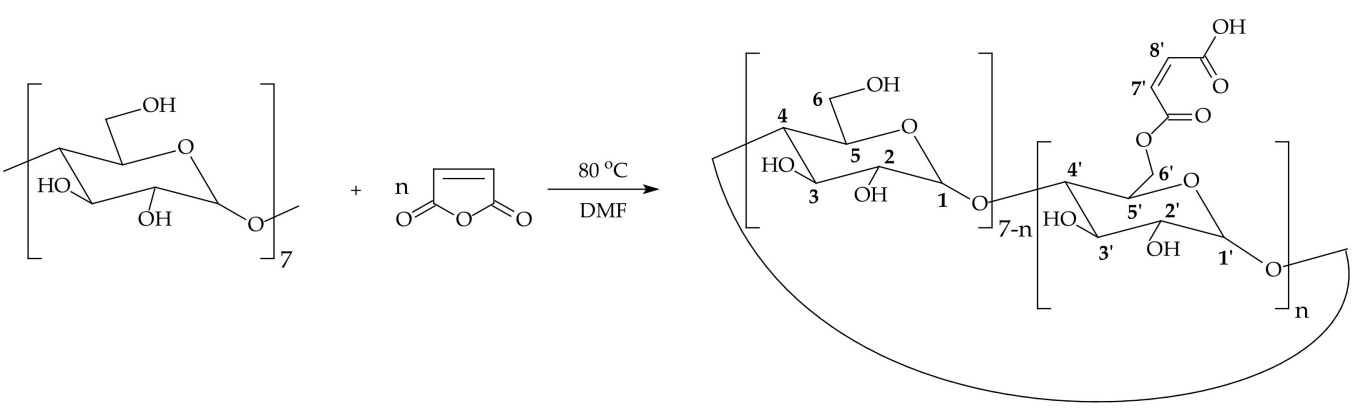

Scheme 1. Addition of maleic anhydride to $\beta$-cyclodextrin.

It is well-known that maleic anhydride and its derivatives do not undergo free radical homopolymerization owing their electron-accepting nature. Therefore, it is necessary to use a second comonomer with electron-donating character. In this work, two types of supports were synthesized, wherein either hydrophilic $N$-vinylpyrrolidone ( $N$-VPy) or hydrophobic styrene was used as the comonomer. Recently, it has been shown that the free radical polymerization of $N$-VPy with a maleic derivative allows the preparation of polymers containing up to $70 \mathrm{wt}$. \% of CD units [40]. Styrene, on the other hand, is known to form an alternating copolymer when used as a comonomer with maleic anhydride. A crosslinking agent (i.e., $N, N^{\prime}$-methylenebisacrylamide (BIS) or ethylene dimethacrylate 
(EGDMA)) was used to reduce the mobility of the polymer chains. Scheme 2 shows the structure of the sorbents used in this work.

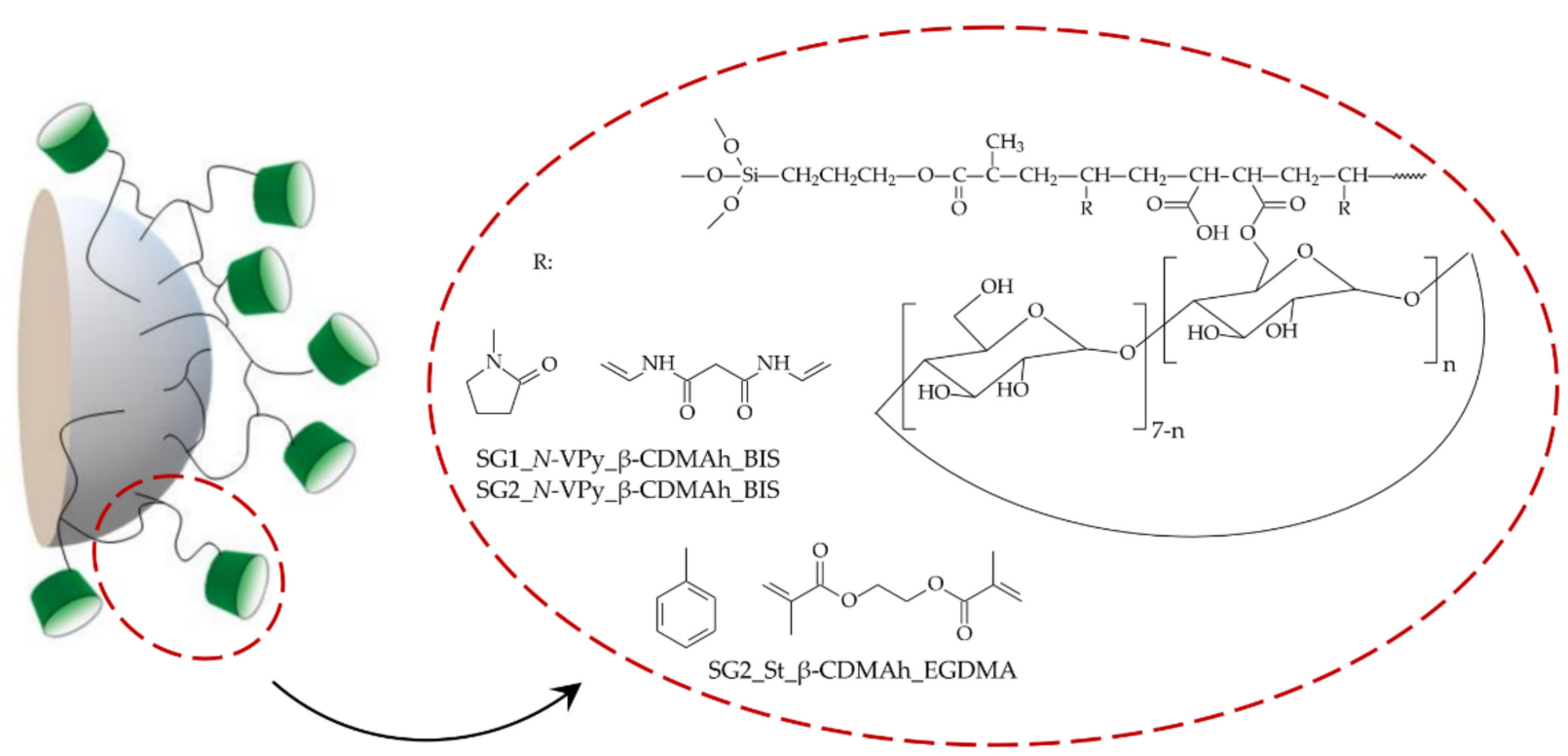

Scheme 2. The structure of the sorbents used in this work.

The obtained sorbents were characterized by attenuated total reflectance (ATR) IR spectroscopy. Figure 5 shows the spectrum of a sorbent prepared by copolymerizing a functional monomer with $N$-VPy on activated silica gel in the presence of BIS as the crosslinking agent using method 1 (SG1_N-VPy_ß-CDMAh_BIS), which was detailed described in Section 3.4.

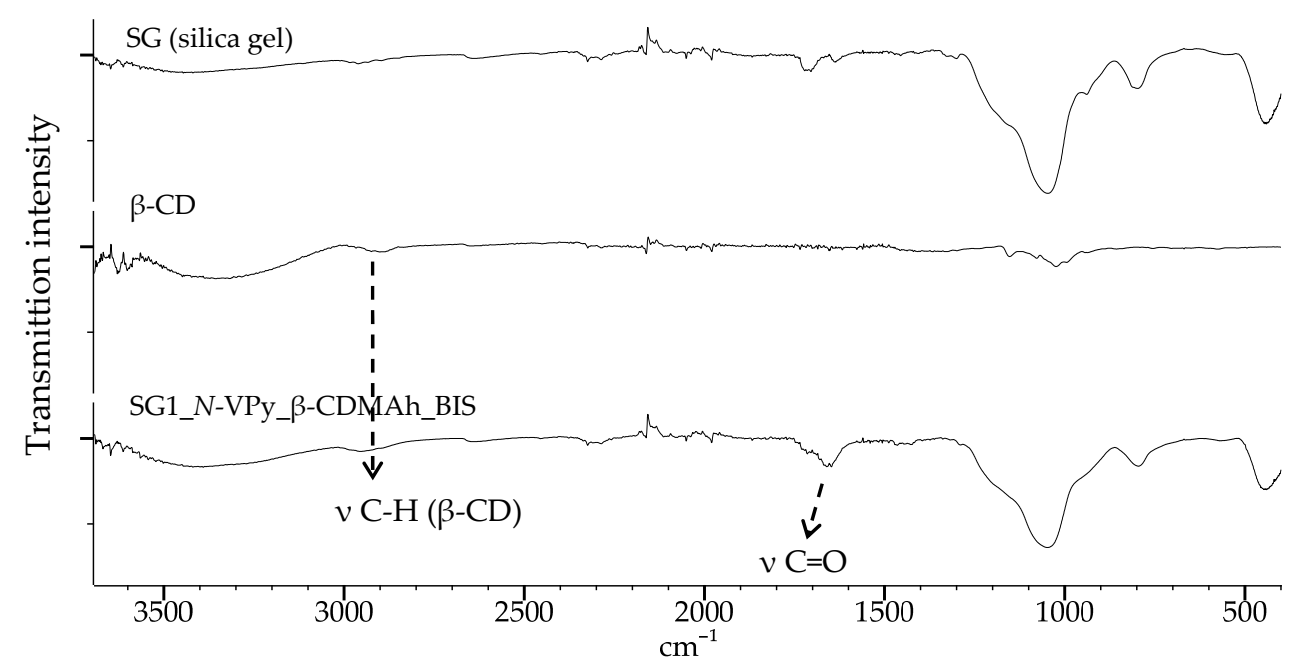

Figure 5. ATR-IR spectra: (top) silica gel; (middle) $\beta-C D$; (bottom) SG1_N-VPy_ $\beta-C D M A h \_B I S$.

The IR spectrum of an analogous polymer on silica gel modified using method 2 (SG2_N-VPy_ $\beta$-CDMAh_BIS) is shown in Figure 6. 


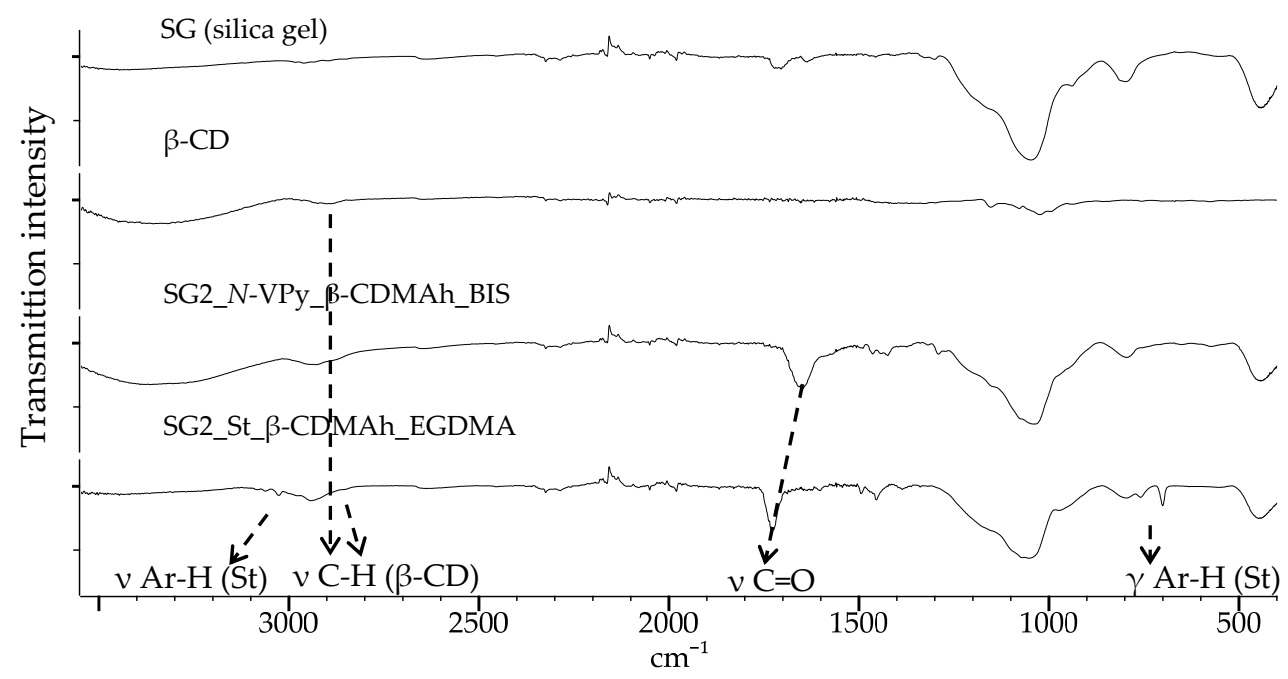

Figure 6. ATR-IR spectra (from the top-down): silica gel; $\beta$-CD; SG2_N-VPy_ $\beta$-CDMAh_BIS; SG2_St_ß-CDMAh_EGDMA.

Comparing these two spectra reveals that the ratio of the intensities of the polymer peaks to the silica gel signals is higher for the sorbent where the polymer was adhered on the silica gel activated via method 2. It can therefore be assumed that the second method of silica gel activation is more effective and allows a greater amount of the polymer to be introduced on the silica surface. Therefore, this approach was applied to prepare the second type of sorbent, which contained styrene units in addition to cyclodextrin units (SG2_St_ß-CDMAh_EGDMA).

In all IR spectra of the obtained sorbents (Figures 5 and 6), a weak band originating from the $\mathrm{C}-\mathrm{H}$ stretching vibrations in the $\beta-\mathrm{CD}$ molecules appears at about $2883 \mathrm{~cm}^{-1}$ (for the SG2_St_ $\beta$-CDMAh_EGDMA sorbent this band is shifted slightly toward smaller wave numbers). In addition, characteristic signals from the stretching vibrations of carbonyl bonds are visible. For SG2_St_ $\beta$-CDMAh_EGDMA sorbent, characteristic signals indicating the presence of an aromatic ring are visible.

\subsection{Recovery Study}

The obtained sorbents were used in the SPE technique for the extraction of NTBC from a buffer solution. The first step in SPE was conditioning of the sorbent packed in the SPE cartridge, which involves washing the sorbent with a solvent to prepare it for efficient extraction of NTBC from solution. In the next step, the NTBC solution prepared in buffer $\left(\mathrm{c}_{\mathrm{NTBC}}=20 \mu \mathrm{g} / \mathrm{mL}, \mathrm{pH}=8.00\right)$ was loaded to the SPE cartridge with the sorbent. The concentration of NTBC corresponded to the content of this drug in patients' blood samples, and the $\mathrm{pH}$ of the prepared solution corresponded to the $\mathrm{pH}$ of the blood samples. Then, analyte was eluted with the appropriate solvent. During the SPE process, effluents (after the sample loading step) and eluates (after the analyte elution step) were collected to estimate the adsorption of NTBC onto the prepared sorbents.

The recoveries (the content of NTBC in the eluate) and the changes in NTBC content in the effluent obtained for commercially available silica gel and the prepared sorbents are presented in Figure 7 with their relative standard deviations (RSD). 


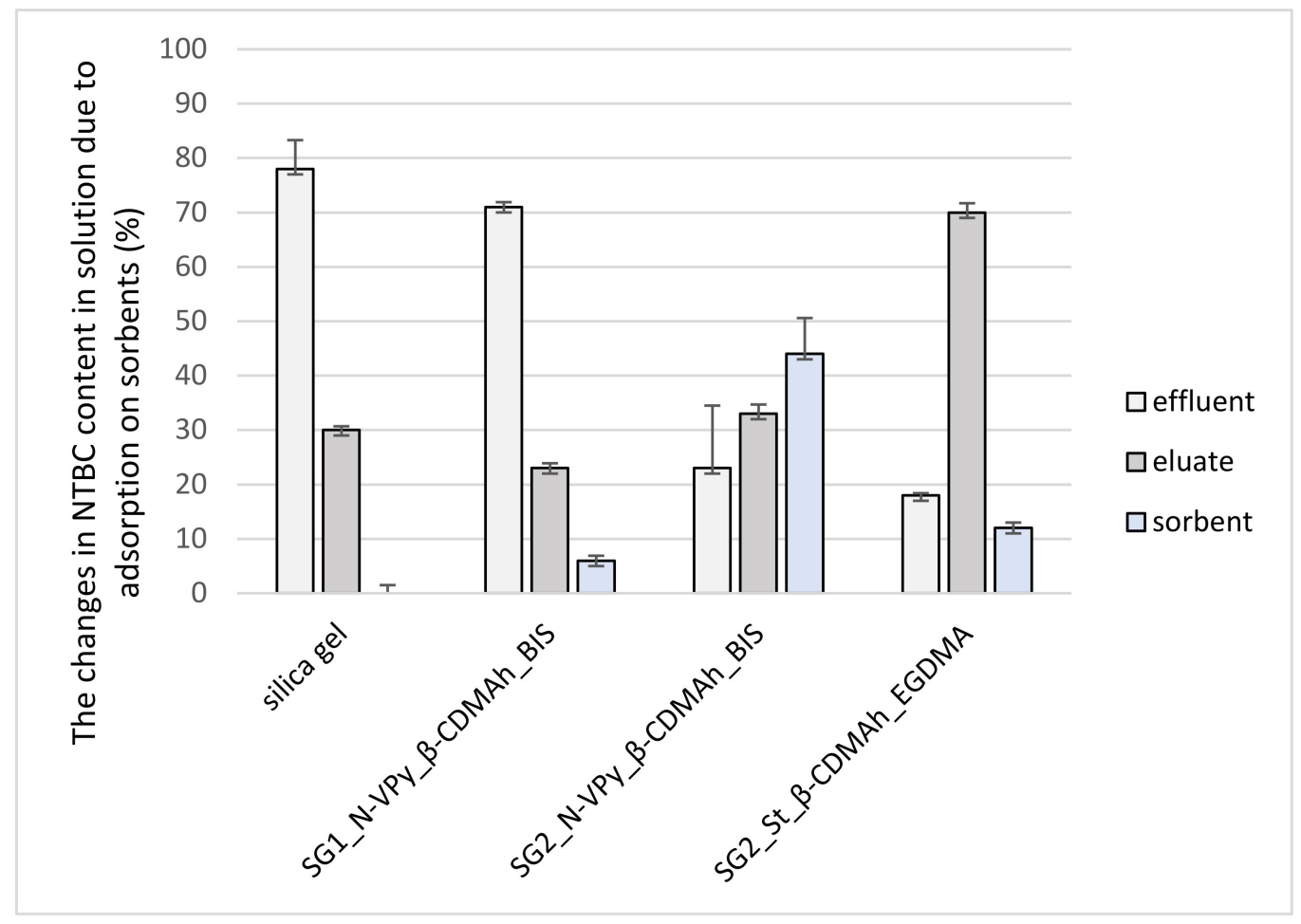

Figure 7. Changes in NTBC content in solution following adsorption to commercially available silica gel and the developed sorbents.

The NTBC recovery achieved by silica gel was low at 30\%. Simultaneously, the high content of NTBC was determined in the effluent, which indicated weak interactions between the NTBC compound and this sorbents. The low recovery for polar silica gel may be explained by the fact that NTBC, as non-polar compound (water solubility $=0.008 \mathrm{~g} / \mathrm{L}$; $\log \mathrm{P}=1.6$ ), poorly interacts with sorbent characterized by polar properties.

The silica gel was activated with two methods. For the first one, SG1_N-VPy_ $\beta$ CDMAh_BIS sorbent was obtained, while for the second-SG2_N-VPy_ $\beta$-CDMAh_BIS. Importantly, the NTBC recovery by SG2_N-VPy_ $\beta-C D M A h \_B I S$ was higher than that of

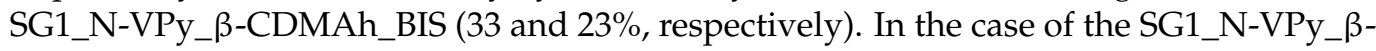
CDMAh_BIS sorbent, the low recovery of NTBC may result from low effectiveness of the silica gel activation, which did not allow for the introduction of polymer on the silica surface (Section 2.2). Therefore, the high content of NTBC was determined in the effluent for this sorbent.

Moreover, high adsorption of NTBC on the sorbent's surface (44\%) was observed for SG2_N-VPy_ $\beta$-CDMAh_BIS. This observation may be due to the low elution strength of the solvent. Considering the low introduction of polymer on the silica surface for SG1_NVPy_ $\beta$-CDMAh_BIS in comparison to SG2_N-VPy_ $\beta$-CDMAh_BIS, the second method of modifying the silica gel surface was used for further studies (Section 2.2).

The highest analyte recovery $(70 \%)$ was observed for SG2_St_ $\beta$-CDMAh_EGDMA (activation of silica gel with the second method), which indicated strong interactions between NTBC and this sorbent. The introduction of styrene increased the hydrophobic properties of the $\beta-C D$ surface. The resulting strong hydrophobic interactions between the sorbent's surface and the analyte, which is a non-polar compound, lead to strong adsorption of the analyte on the sorbent.

The experimental results demonstrated high precision (i.e., RSD in the range: $0.3-11.5 \%$ ). Based on the analysis of variance (ANOVA) performed using the MATLAB software, the obtained results show statistically significant differences between particular sorbents $(p<0.05)$. 


\subsection{Validation Study}

The developed method involving the novel sorbent SG2_St_ $\beta$-CDMAh_EGDMA were validated in terms of linearity, sensitivity (i.e., limit of quantification, LOQ), accuracy (i.e., recovery, RE), precision (i.e., RSD), and matrix effects (ME). The detailed validation parameters of the elaborated method are presented in Table 1.

Table 1. Validation parameters for the elaborated method involving the new sorbent SG2_St_ß-CDMAh_EGDMA.

\begin{tabular}{|c|c|c|c|c|c|c|c|c|c|}
\hline \multirow{2}{*}{ Analyte } & \multirow{2}{*}{$\begin{array}{c}\text { Range } \\
\left(\mu \mathrm{g} \mathrm{mL}^{-1}\right)\end{array}$} & \multirow{2}{*}{$\begin{array}{l}\text { Linearity } \\
\qquad\left(R^{2}\right)\end{array}$} & \multirow{2}{*}{$\begin{array}{c}\text { LOD } \\
\left(\mu \mathrm{g} \mathrm{mL}^{-1}\right)\end{array}$} & \multirow{2}{*}{$\begin{array}{c}\mathrm{LOQ} \\
\left(\mu \mathrm{g} \mathrm{mL}^{-1}\right)\end{array}$} & \multirow{2}{*}{$\begin{array}{l}\text { ME } \\
(\%)\end{array}$} & \multicolumn{2}{|c|}{$\begin{array}{c}\text { Recovery } \pm \text { RSD } \\
(\%)\end{array}$} & \multicolumn{2}{|c|}{$\begin{array}{c}\text { Interday Precision } \\
\text { (\%RSD) }\end{array}$} \\
\hline & & & & & & $5 \mu \mathrm{g} \mathrm{mL}^{-1}$ & $15 \mu \mathrm{g} \mathrm{mL}^{-1}$ & $5 \mu \mathrm{g} \mathrm{mL}^{-1}$ & $15 \mu \mathrm{g} \mathrm{mL}^{-1}$ \\
\hline NTBC & $1.0-25.0$ & 0.9996 & 0.03 & 0.09 & 17.0 & $68.0 \pm 5.8$ & $70.0 \pm 3.8$ & 9.3 & 3.6 \\
\hline
\end{tabular}

A calibration curve prepared with solutions covering the concentration range 1.0-25.0 $\mu \mathrm{g} \mathrm{mL}^{-1}$ revealed that NTBC exhibited good linearity (coefficient of determination $\mathrm{R}^{2}=0.9996$ ).

The LOQ was determined to be $0.09 \mu \mathrm{g} \mathrm{mL}^{-1}$, which indicates that the described method involving the new sorbent can be applied for the extraction and determination of NTBC concentrations in patient blood samples.

The accuracy, expressed as the recovery of NTBC, was in the range $68.0-70.0 \%$, while the precision of the method was in the range 3.6-9.3\%.

The ME was not considered significant because its value (17\%) was lower than $20 \%$. Therefore, it was concluded that the signal of the analyte was not influenced by coextracted matrix compounds.

\section{Materials and Methods}

\subsection{Standards and Reagents}

TSP and NTBC standard (HPLC grade, $\geq 95 \%$ ) was purchased from Sigma Aldrich (St. Louis, MO, USA).

Individual stock solutions of NTBC were prepared in methanol $(\mathrm{MeOH})$ at concentrations of $1 \mathrm{mg} / \mathrm{mL}$ and stored in a refrigerator $\left(7^{\circ} \mathrm{C}\right)$. Working standard solutions were prepared daily by diluting the stock solutions with $\mathrm{MeOH}$.

Deuterium oxide was obtained from The Radioisotope Production and Distribution Centre (Świerk, Poland).

Acetonitrile and trifluoroacetic acid (HPLC grade) were purchased from VWR (Gdańsk, Poland). Deionized water was obtained from Millipore (Burlington, MA, USA).

$N$-VPy ( $\geq 99 \%$ ) and $\gamma$-MAPS (98\%) were purchased from Sigma Aldrich (Saint Louis, $\mathrm{MO}, \mathrm{USA})$.

$N, N$-Dimethylformamide (DMF, 99.8\%), dimethyl sulfoxide (DMSO, 99.7\%), maleic anhydride (MAh, 99\%), styrene (99\%), 2,2'-azobis(2-methylpropionitrile) (AIBN, 98\%), $\beta$-CD $(98 \%)$, EGDMA ( $98 \%$ ), and BIS $(96 \%)$ were purchased from Chemiatrade (Gliwice, Poland). The DMF was dried over calcium hydride, filtered, and distilled under reduced pressure $\left(8 \mathrm{mmHg} / 31^{\circ} \mathrm{C}\right)$, and $\beta-\mathrm{CD}$ was dried in an oven at $120^{\circ} \mathrm{C}$ for $24 \mathrm{~h}$.

Acetone, chloroform, $\mathrm{MeOH}$, and toluene (analytical grade) were purchased from ChemLand (Stargard, Poland); acetone was dried over magnesium sulphate $\left(\mathrm{MgSO}_{4}\right)$.

Sodium dihydrogen phosphate dihydrate $\left(\mathrm{NaH}_{2} \mathrm{PO}_{4} \cdot 2 \mathrm{H}_{2} \mathrm{O}\right)$, sodium phosphate dibasic dodecahydrate $\left(\mathrm{Na}_{2} \mathrm{HPO}_{4} \cdot 12 \mathrm{H}_{2} \mathrm{O}\right)$, sodium bicarbonate $\left(\mathrm{NaHCO}_{3}\right)$, sodium chloride, calcium chloride, and potassium chloride (all analytical grade) were purchased from $\mathrm{POCH}$ (Gliwice, Poland).

$\mathrm{MgSO}_{4}$ (dried, 97\%) was purchased from Fisher Scientific (Hampton, NH, USA). Silica gel $(0.05-0.20 \mathrm{~mm})$ was purchased from Merck (Darmstadt, Germany). 


\subsection{Synthesis of $\beta$-Cyclodextrin Maleate}

$\beta$-cyclodextrin maleate ( $\beta$-CDMAh) was synthesized by adding maleic anhydride to $\beta$ $\mathrm{CD}$ (Scheme 1), according to a modified version of a published procedure [39]. Specifically, in a $50 \mathrm{~mL}$ round-bottom flask, $5.00 \mathrm{~g}(4.4 \mathrm{mmol})$ of dried $\beta-C D$ was dissolved in $30 \mathrm{~mL}$ of dehydrated DMF. Then, $1.10 \mathrm{~g}$ (11.22 mmol) of maleic anhydride was added. The reaction was allowed to proceed in a sealed flask with continuous stirring at $80^{\circ} \mathrm{C}$ for $15 \mathrm{~h}$. The crude product was precipitated in acetone and subjected to continuous extraction in acetone using a Soxhlet apparatus for $48 \mathrm{~h}$. The residual solvent was evaporated from the product under reduced pressure, and $4.57 \mathrm{~g}$ of pure product was obtained (69.2\% yield). $\beta$-CDMAh was characterized by NMR spectroscopy:

${ }^{1} \mathrm{H}-\mathrm{NMR}\left(600 \mathrm{MHz}, \mathrm{D}_{2} \mathrm{O}\right): \delta(\mathrm{TSP})$ 6.61-6.51 $\left(\mathrm{m},-\mathrm{CH}=, 7^{\prime}\right) ; 5.82-5.69\left(\mathrm{~m},-\mathrm{CH}=, 8^{\prime}\right) ; 5.03$ $\left(\mathrm{m}, 1^{\prime}\right) ; 4.96(\mathrm{~d}, J=3,7 \mathrm{~Hz}, 1) ; 4.43\left(\mathrm{~m}, 5^{\prime}\right) ; 4.24\left(\mathrm{~m}\right.$, one of $\left.6^{\prime}\right) ; 3.88\left(\mathrm{~m}, 3^{\prime}\right) ; 3.85-3.59(\mathrm{~m}, 3,6,5$, one of $\left.6^{\prime}\right) ; 3.58-3.47\left(\mathrm{~m}, 2^{\prime}, 2,4^{\prime}, 4\right)$.

\subsection{NMR Characterization of $\beta-C D / N T B C$ Complexes}

The interactions between the $\beta-C D$ and NTBC were evaluated based on their ${ }^{1} \mathrm{H}-$ NMR spectra recorded at $25^{\circ} \mathrm{C}$ using a $600 \mathrm{MHz}$ Varian spectrometer in $\mathrm{D}_{2} \mathrm{O}$ (TSP was used as an internal reference). All of the tested solutions were prepared in deuterated phosphate-buffered solution $(0.1 \mathrm{M}, \mathrm{pD}=8.00)$. The buffer $\mathrm{pH}(\mathrm{pD})$ was close to that of artificial plasma (i.e., corresponding to the $\mathrm{pH}$ of blood) [41]. In addition, NTBC is sparingly soluble in water $\left(0.008 \mathrm{mg} \mathrm{mL}^{-1}\right)$, although its solubility increases in alkaline solutions $\left(0.5 \mathrm{mg} \mathrm{mL}^{-1}\right)$ [42].

To make the phosphate-buffered solution with $\mathrm{pD}=8.00$, two 0.2 Mstock solutions of suitable salts were first prepared in deuterated water: solution $(A)$ contained $\mathrm{Na}_{2} \mathrm{HPO}_{4} \cdot 12 \mathrm{H}_{2} \mathrm{O}$, and solution $(B)$ contained $\mathrm{NaH}_{2} \mathrm{PO}_{4} \cdot 2 \mathrm{H}_{2} \mathrm{O}$. Next, $5 \mathrm{~mL}$ of the solution obtained by mixing solutions $A$ and $B$ in a 10:1 volume ratio was transferred to a 10-mL volumetric flask, which was then filled to the mark with deuterated water.

\subsubsection{Continuous Variation Method for Determining the Stoichiometry}

Equimolar solutions $(10 \mathrm{mM})$ of $\beta-C D$ and NTBC were prepared in $\mathrm{D}_{2} \mathrm{O}$ buffer solution and distributed among 11 NMR tubes such that the molar fractions of $\beta-C D$ varied between 0:1 and 1:0 (with a constant sample volume of $0.6 \mathrm{~mL}$ ). A solution of TSP (in D2O) placed in melting-point capillary was used as an external reference. Standard ${ }^{1} \mathrm{H}-\mathrm{NMR}$ spectra were acquired with a relaxation delay of $5 \mathrm{~s}$. The exact values of the molar fractions were determined based on the intensity of the appropriate signals. Job's plots were constructed according to the chemical shifts of the aromatic proton signals of NTBC, as well as $\mathrm{H}^{3}$ and $\mathrm{H}^{5}$ of $\beta-\mathrm{CD}$.

\subsubsection{D-ROESY}

For 2D-ROESY measurements, a solution of $\beta-C D(15 \mathrm{mM})$ and NTBC $(60 \mathrm{mM})$ was prepared in deuterated phosphate buffer; no reference was added, and the chemical shifts were calibrated based on the residual water signal at $4.790 \mathrm{ppm}$ [43]. ROESY experiments were carried out on a $600 \mathrm{MHz}$ spectrometer with a mixing time of $500 \mathrm{~ms}$.

\subsubsection{Titration Studies for Evaluating the Association Constants}

Two stock solutions were prepared in $\mathrm{D}_{2} \mathrm{O}$ buffer solution: one containing only $\beta-\mathrm{CD}$ $(10 \mathrm{mM})$, and the other containing $\beta-\mathrm{CD}(10 \mathrm{mM})$ and NTBC $(40 \mathrm{mM})$. These solutions were mixed in an NMR tube such that the molar ratio of NTBC / $\beta-C D$ varied from 0.0 to 4.0 , while keeping the concentration of $\beta-C D$ constant at $10 \mathrm{mM}$. A solution of TSP in $\mathrm{D}_{2} \mathrm{O}$ placed in a capillary tube was used as an external reference. Standard ${ }^{1} \mathrm{H}-\mathrm{NMR}$ spectra were acquired with a relaxation delay of $5 \mathrm{~s}$. The exact values of the molar ratio of NTBC to $\beta-C D$ were calculated based on the appropriate ${ }^{1} \mathrm{H}-\mathrm{NMR}$ signal integrations. 


\subsection{Modification of Silica Gel}

Before the experiments, silica gel was dried at $120^{\circ} \mathrm{C}$ for $24 \mathrm{~h}$ to remove adsorbed water on its surface.

Two methods were used to obtain activated silica gel surfaces. The first method was performed according to a report by Choi and coworkers [44]. Specifically, $10 \mathrm{~g}$ of silica gel was dispersed in $160 \mathrm{~mL}$ toluene in a $250-\mathrm{mL}$ round-bottomed flask. Subsequently, $9.6 \mathrm{~mL}$ of $\gamma$-MAPS was added to the solution under nitrogen at $0{ }^{\circ} \mathrm{C}$. The mixture was stirred at $80^{\circ} \mathrm{C}$ for 3 days. After filtration and washing with methanol, the modified silica gel ( $\gamma$-MAPS SG 1) was dried to a constant weight.

The second modification method was performed in the presence of catalytic amounts of acidic acid. Specifically, $10 \mathrm{~g}$ of silica gel was dispersed in $126 \mathrm{~mL}$ of acetone in a $250-\mathrm{mL}$ round-bottomed flask. Then, $9.6 \mathrm{~mL}$ of $\gamma$-MAPS and four drops of acetic acid were added. The mixture was stirred at the room temperature for $4 \mathrm{~h}$. After filtration and washing with acetone, the modified silica gel ( $\gamma$-MAPS SG 2 ) was dried to a constant weight.

\subsection{Surface Grafting of $\beta$-CDMAh on Silica Gel}

Two polymers grafted on the surface of modified silica gel were tested. In all cases, $\beta$-CDMAh (synthesis described in Section 3.2) was used as the functional monomer. Polymeric sorbents were prepared using a thermally initiated free radical polymerization method. The detailed synthetic conditions are presented in Table 2.

Table 2. Detailed conditions for the sorbent syntheses.

\begin{tabular}{|c|c|c|c|c|c|c|c|c|c|c|c|c|}
\hline Sorbent & Silica Gel & Mass (g) & $\begin{array}{l}\text { Functional } \\
\text { Monomer }\end{array}$ & Mass (g) & Solvent & $\begin{array}{l}\text { Volume } \\
(\mathrm{mL})\end{array}$ & Comonomer & $\begin{array}{l}\text { Number } \\
\text { of Moles } \\
(\mathrm{g} / \mathrm{mmol})\end{array}$ & $\begin{array}{c}\text { Cross- } \\
\text { Linking } \\
\text { Agent }\end{array}$ & $\begin{array}{l}\text { Content } \\
(\mathrm{g} / \mathrm{mmol})\end{array}$ & $\begin{array}{c}\text { Polymerization } \\
\text { Initiator }\end{array}$ & Mass (g) \\
\hline $\begin{array}{c}\text { SG1_N- } \\
\text { VPy_B- } \\
\text { CDMAh_BIS }\end{array}$ & SG 1 & \multirow{3}{*}{3.0} & \multirow{3}{*}{$\beta$-CDMAh } & \multirow{3}{*}{1.0} & $\mathrm{H}_{2} \mathrm{O}$ & \multirow{3}{*}{7.6} & $N$-VPy & $0.6 / 5.0$ & BIS & \multirow{2}{*}{$0.05 / 0.3$} & \multirow{3}{*}{ AIBN } & \multirow{3}{*}{0.023} \\
\hline $\begin{array}{c}\text { SG2_N- } \\
\text { VPy_B- } \\
\text { CDMAh_BIS }\end{array}$ & \multirow{2}{*}{ SG 2} & & & & $\mathrm{H}_{2} \mathrm{O}$ & & $N$-VPy & $0.6 / 5.0$ & BIS & & & \\
\hline $\begin{array}{l}\text { SG2_St_ } \beta \text { - } \\
\text { CDMAh_EGDMA }\end{array}$ & & & & & DMSO & & styrene & $0.29 / 2.7$ & EGDMA & $0.19 / 1.0$ & & \\
\hline
\end{tabular}

The functional monomer was dissolved in the solvent, and then, the comonomer, crosslinking agent, and polymerization initiator were added. The mixture was transferred to a reaction vessel that contained previously weighed modified silica gel. The contents of the vessel were degassed via freeze-pump-thaw cycling in order to remove oxygen, which can inhibit the polymerization. The reaction vessel under a nitrogen atmosphere was stirred at $80^{\circ} \mathrm{C}$ for $24 \mathrm{~h}$. In the next step, the obtained sorbent was washed with water, methanol, and chloroform, and then dried to a constant weight.

\subsection{Fourier Transform Infrared Spectroscopy}

The obtained sorbents were characterized by FTIR. The FTIR spectra were recorded using an FTIR 6700 spectrometer (Nicolet, Thermo Fisher Scientific Inc.) equipped with a diamond crystal Smart OrbitTM accessory working in ATR mode. The FTIR spectra of the samples were measured in the range from 500 to $4000 \mathrm{~cm}^{-1}$ with 64 accumulations. The software OM-NIC 8.1 (Thermo Fisher Scientific Inc.) applied an advanced ATR correction of the recorded spectra.

\subsection{SPE Procedure}

First, $300 \mathrm{mg}$ of silica gel and of each polymer based on modified silica gel were separately packed in 3-mL polypropylene SPE columns and secured at both ends with polyethylene frits. The sorbent was conditioned with $3 \mathrm{~mL}$ of methanol. Then, $1 \mathrm{~mL}$ of a standard solution of NTBC $(20 \mu \mathrm{g} / \mathrm{mL})$ in phosphate buffer $(\mathrm{pH}=8.00)$ was loaded onto the column and the effluent was collected. The analyte was eluted with $1 \mathrm{~mL}$ of methanol, and the eluate was also collected for analysis. After the elution step, the sorbent was washed with $3 \mathrm{~mL}$ of methanol and dried under vacuum. 
The SPE procedure was performed in three replicates for each sorbent $(n=3)$.

\subsection{Chromatographic Analysis}

The NTBC contents in the collected effluents and eluents were determined using a high performance liquid chromatograph (HPLC; Merck Hitachi, Tokyo, Japan) equipped with an L-7100 pump, a D-7000 interface, a diode array detector (DAD) L-4500A, an autosampler L-7200, and a column-thermostat Jetstream 2 Plus column. TSKgel ODS-100V (octadecyl, $150 \mathrm{~mm} \times 4.6 \mathrm{~mm}, 5 \mu \mathrm{m}$ particle size, TOSOH Bioscience, Tokyo, Japan) was used as the chromatographic column at $24^{\circ} \mathrm{C}$. The mobile phase consisted of ACN (A) and $0.05 \%$ TFA in water (B) in isocratic mode $(80 \% \mathrm{~A})$, with a flow rate of $0.5 \mathrm{~mL} / \mathrm{min}$ and an analytical time of $10 \mathrm{~min}$. The injection volume was $20 \mu \mathrm{L}$, and quantitative analysis was performed at the analytical wavelength $\lambda_{\mathrm{MAX}}=271 \mathrm{~nm}$. The chromatogram of NTBC $(\mathrm{c}=20 \mu \mathrm{g} / \mathrm{mL})$ was presented in Figure 8.

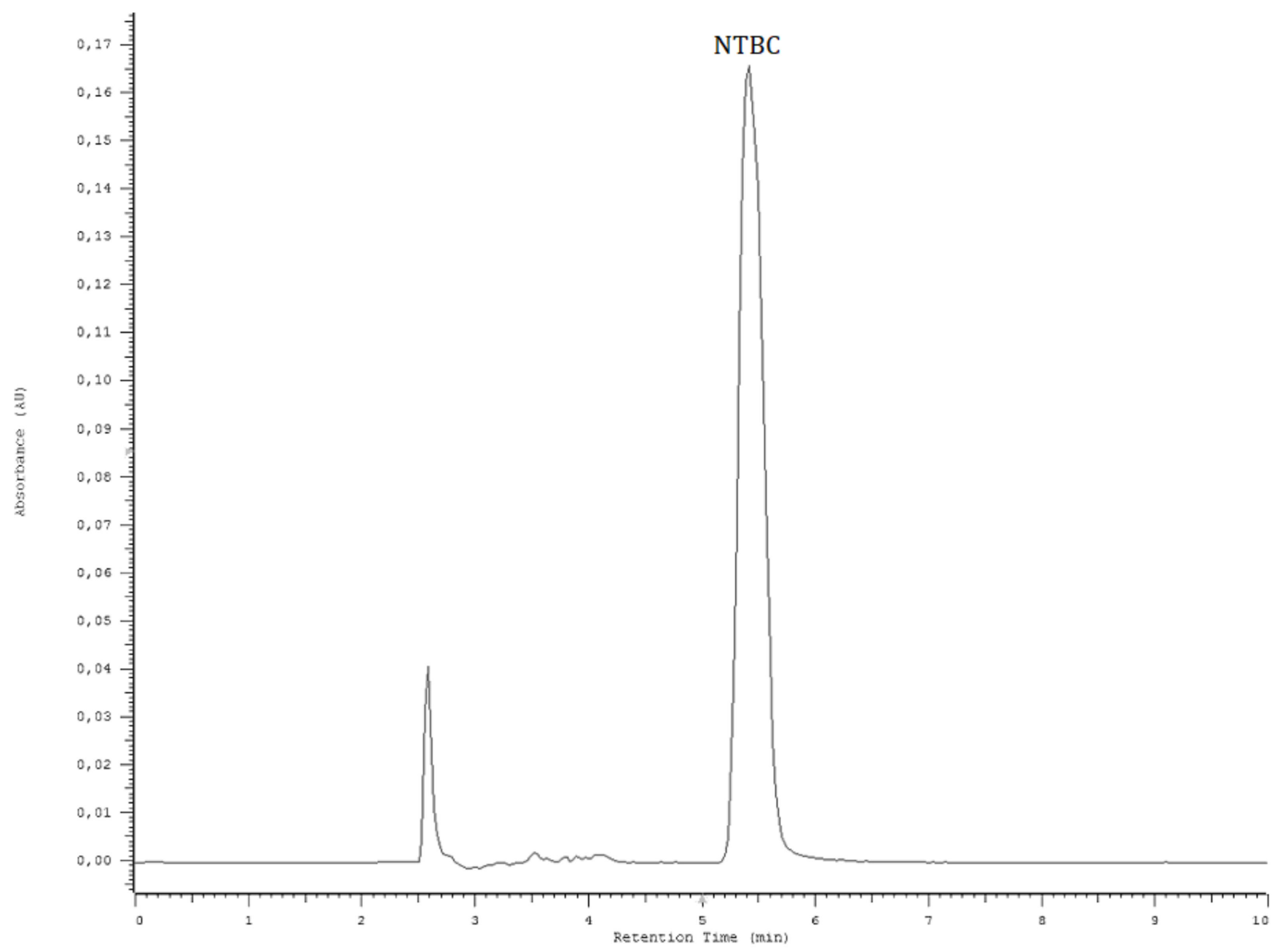

Figure 8. The chromatogram of NTBC standard solution prepared in methanol ( $\mathrm{c}=20 \mu \mathrm{g} / \mathrm{mL})$.

The chromatographic analyses of effluents and eluates were performed in three replicates $(n=3)$.

\subsection{Analytical Method Validation}

The analytical method was validated based on the sorbent that achieved the highest analyte RE (the highest NTBC content in the eluate). The matrix comprised artificial plasma prepared according to a method reported by Liu and coworkers [41], without bovine serum albumin (BSA). 
Six calibration points in the range of $1-25 \mu \mathrm{g} / \mathrm{mL}$ were prepared in artificial plasma (in three repetitions; $\mathrm{n}=3$ ) to obtain information regarding the linearity, sensitivity (LOQ), and ME of the method. Moreover, the NTBC recovery, and the intraday and interday precision (RSD) at 5 and $15 \mu \mathrm{g} / \mathrm{mL}$ in the artificial plasma were evaluated $(\mathrm{n}=3)$.

\section{Conclusions}

A new polymeric sorbent containing derivatives of $\beta$-cyclodextrin grafted on silica gel was developed, and it was successfully employed for the extraction of NTBC from model physiological fluids. Its demonstrated effectiveness for NTBC extraction from artificial plasma was a result of the formation and geometry of an inclusion complex comprising NTBC and $\beta-C D$.

The elaborated SPE-HPLC-DAD method involving the novel polymeric sorbent containing $\beta$-cyclodextrin derivatives grafted on silica gel exhibited good linearity, sensitivity, accuracy, and precision and is thus deemed suitable for the determination of NTBC in patients' blood samples.

During treatment with NTBC, the concentration of L-tyrosine may increase in patients' blood due to inhibition of the metabolic pathway of this amino acid by drug [3].

L-tyrosine, similarly to NTBC, has a tendency to form inclusion complexes with $\beta$-CD. The values of association constants reported in the literature, $K=105.00 \mathrm{M}^{-1}$ [45] and $\mathrm{K}=60.25 \mathrm{M}^{-1}$ [46], are close to the values for the complex of $\beta-C D$ with NTBC, determined in the present work. Therefore, the selectivity of the developed sorbents will be studied in the future, especially in respect to the L-tyrosine.

Author Contributions: Conceptualization, M.D.; methodology, M.D. and A.K.-W.; software, M.D. and A.K.-W.; validation, M.D.; formal analysis, H.B.; investigation, M.D. and A.K.-W.; resources, M.D. and A.K.-W.; data curation, M.D. and A.K.-W.; writing-original draft preparation, M.D. and A.K.-W.; writing-review and editing, H.B.; visualization, M.D. and A.K.-W.; supervision, M.D.; project administration, M.D.; funding acquisition, M.D. All authors have read and agreed to the published version of the manuscript.

Funding: This work was supported by the Excellence Initiative-Research University program implemented at the Silesian University of Technology, 2021.

Institutional Review Board Statement: Not applicable.

Informed Consent Statement: Not applicable.

Data Availability Statement: Not available.

Conflicts of Interest: The authors declare no conflict of interest.

Samples Availability: Samples of the compounds are not available from the authors.

\section{References}

1. Knudsen, C.G.; Lee, D.L.; Michaely, W.J.; Chin, H.-L.; Nguyen, N.H.; Rusay, R.J.; Cromartie, T.H.; Gray, R.; Lake, B.H.; Fraser, T.E.M.; et al. Discovery of the triketone class of HPPD inhibiting herbicides and their relationship to naturally occurring $\$ \beta \$$-triketones. In Allelopathy in Ecological Agriculture and Forestry, Proceedings of the III International Congress on Allelopathy in Ecological Agriculture and Forestry, Dharwad, India, 18-21 August 1998; Narwal, S.S., Hoagland, R.E., Dilday, R.H., Reigosa, M.J., Eds.; Springer Netherlands: Dordrecht, The Netherlands, 2000; pp. 101-111, ISBN 978-94-011-4173-4.

2. Khedr, M.; Judd, S.; Briggs, M.C.; Hughes, A.T.; Milan, A.M.; Stewart, R.M.K.; Lock, E.A.; Gallagher, J.A.; Ranganath, L.R. Asymptomatic corneal keratopathy secondary to hypertyrosinaemia following low dose nitisinone and a literature review of tyrosine keratopathy in alkaptonuria. In JIMD Reports; Morava, E., Baumgartner, M., Patterson, M., Rahman, S., Zschocke, J., Peters, V., Eds.; Springer: Berlin/Heidelberg, Germany, 2018; Volume 40, pp. 31-37, ISBN 978-3-662-57880-3.

3. Lock, E.; Ranganath, L.R.; Timmis, O. The role of nitisinone in tyrosine pathway disorders. Curr. Rheumatol. Rep. 2014, 16, 457. [CrossRef] [PubMed]

4. Aktuglu-Zeybek, A.C.; Zubarioglu, T. Nitisinone: A review. Orphan Drugs Res. Rev. 2017, 7, 25-35. [CrossRef]

5. Das, A.M. Clinical utility of nitisinone for the treatment of hereditary tyrosinemia type-1 (HT-1). Appl. Clin. Genet. 2017, 10, 43-48. [CrossRef] [PubMed] 
6. Larochelle, J.; Alvarez, F.; Bussières, J.F.; Chevalier, I.; Dallaire, L.; Dubois, J.; Faucher, F.; Fenyves, D.; Goodyer, P.; Grenier, A.; et al. Effect of nitisinone (NTBC) treatment on the clinical course of hepatorenal tyrosinemia in Québec. Mol. Genet. Metab. 2012, 107, 49-54. [CrossRef]

7. Couce, M.L.; Sánchez-Pintos, P.; Aldámiz-Echevarría, L.; Vitoria, I.; Navas, V.; Martín-Hernández, E.; García-Volpe, C.; Pintos, G.; Peña-Quintana, L.; Hernández, T.; et al. Evolution of tyrosinemia type 1 disease in patients treated with nitisinone in Spain. Medicine 2019, 98, e17303. [CrossRef]

8. Sloboda, N.; Wiedemann, A.; Merten, M.; Alqhatani, A.; Jeannesson, E.; Blum, A.; Henn-Ménétré, S.; Guéant, J.L.; Renard, E.; Feillet, F. Efficacy of low dose nitisinone in the management of alkaptonuria. Mol. Genet. Metab. 2019, 127, 184-190. [CrossRef]

9. Häberle, J. Suitability of nitisinone for alkaptonuria. Lancet Diabetes Endocrinol. 2020, 8, 732-733. [CrossRef]

10. Stevens, M.; Frobisher, C.; Hawkins, M.; Jenney, M.; Lancashire, E.; Reulen, R.; Taylor, A.; Winter, D. The British Childhood Cancer Survivor Study: Objectives, methods, population structure, response rates and initial descriptive information. Pediatr. Blood Cancer 2008, 50, 1018-1025. [CrossRef]

11. Suwannarat, P.; O’Brien, K.; Perry, M.B.; Sebring, N.; Bernardini, I.; Kaiser-Kupfer, M.I.; Rubin, B.I.; Tsilou, E.; Gerber, L.H.; Gahl, W.A. Use of nitisinone in patients with alkaptonuria. Metabolism 2005, 54, 719-728. [CrossRef]

12. Prieto, J.A.; Andrade, F.; Lage, S.; Aldámiz-Echevarría, L. Comparison of plasma and dry blood spots as samples for the determination of nitisinone (NTBC) by high-performance liquid chromatography-tandem mass spectrometry. Study of the stability of the samples at different temperatures. J. Chromatogr. B Anal. Technol. Biomed. Life Sci. 2011, 879, 671-676. [CrossRef] [PubMed]

13. Huck, C.W.; Bonn, G.K. Recent developments in polymer-based sorbents for solid-phase extraction. J. Chromatogr. A 2000, 885, 51-72. [CrossRef]

14. Pawliszyn, J. Sample preparation: Quo vadis? Anal. Chem. 2003, 75, 2543-2558. [CrossRef]

15. Chen, Y.; Guo, Z.; Wang, X.; Qiu, C. Sample preparation. J. Chromatogr. A 2008, 1184, 191-219. [CrossRef] [PubMed]

16. Manahan, S.E. Environmental Chemistry; CRC press: Boca Raton, FL, USA, 2017.

17. Xia, L.; Yang, J.; Su, R.; Zhou, W.; Zhang, Y.; Zhong, Y.; Huang, S.; Chen, Y.; Li, G. Recent Progress in Fast Sample Preparation Techniques. Anal. Chem. 2020, 92, 34-48. [CrossRef] [PubMed]

18. ScienceDirect. Available online: https://www.sciencedirect.com/search?qs=solid\%20phase\%20extraction (accessed on 18 August 2021).

19. Poole, C.F. New trends in solid-phase extraction. TrAC Trends Anal. Chem. 2003, 22, 362-373. [CrossRef]

20. Augusto, F.; Hantao, L.W.; Mogollón, N.G.S.; Braga, S.C.G.N. New materials and trends in sorbents for solid-phase extraction. TrAC Trends Anal. Chem. 2013, 43, 14-23. [CrossRef]

21. Płotka-Wasylka, J.; Szczepańska, N.; de la Guardia, M.; Namieśnik, J. Modern trends in solid phase extraction: New sorbent media. TrAC Trends Anal. Chem. 2016, 77, 23-43. [CrossRef]

22. Appell, M.; Jackson, M.A. Synthesis and evaluation of cyclodextrin-based polymers for patulin extraction from aqueous solutions. J. Incl. Phenom. Macrocycl. Chem. 2010, 68, 117-122. [CrossRef]

23. Li, Y.; Lu, P.; Cheng, J.; Wang, Q.; He, C. Simultaneous solid-phase extraction and determination of three bisphenols in water samples and orange juice by a porous $\beta$-cyclodextrin polymer. Food Anal. Methods 2018, 11, 1476-1484. [CrossRef]

24. Zhang, J.; Liu, D.; Shi, Y.; Sun, C.; Niu, M.; Wang, R.; Hu, F.; Xiao, D.; He, H. Determination of quinolones in wastewater by porous $\beta$-cyclodextrin polymer based solid-phase extraction coupled with HPLC. J. Chromatogr. B Anal. Technol. Biomed. Life Sci. 2017, 1068-1069, 24-32. [CrossRef]

25. Gentili, A. Cyclodextrin-based sorbents for solid phase extraction. J. Chromatogr. A 2020, 1609, 460654. [CrossRef]

26. Crini, G.; Fourmentin, S.; Fenyvesi, É.; Torri, G.; Fourmentin, M.; Morin-Crini, N. Cyclodextrins, from molecules to applications. Environ. Chem. Lett. 2018, 16, 1361-1375. [CrossRef]

27. Qin, L.; He, X.W.; Li, W.Y.; Zhang, Y.K. Molecularly imprinted polymer prepared with bonded $\beta$-cyclodextrin and acrylamide on functionalized silica gel for selective recognition of tryptophan in aqueous media. J. Chromatogr. A 2008, 1187, 94-102. [CrossRef] [PubMed]

28. Martina, K.; Baricco, F.; Berlier, G.; Caporaso, M.; Cravotto, G. Efficient green protocols for preparation of highly functionalized $\beta$-cyclodextrin-grafted silica. ACS Sustain. Chem. Eng. 2014, 2, 2595-2603. [CrossRef]

29. Liu, H.J.; Jing, P.F.; Liu, X.Y.; Du, K.J.; Sun, Y.K. Synthesis of $\beta$-cyclodextrin functionalized silica gel and its application for adsorption of uranium(VI). J. Radioanal. Nucl. Chem. 2016, 310, 263-270. [CrossRef]

30. Morin-Crini, N.; Fourmentin, M.; Fourmentin, S.; Torri, G.; Crini, G. Synthesis of silica materials containing cyclodextrin and their applications in wastewater treatment. Environ. Chem. Lett. 2019, 17, 683-696. [CrossRef]

31. Mitrev, Y.; Simova, S.; Jeannerat, D. NMR analysis of weak molecular interactions using slice-selective experiments via study of concentration gradients in agar gels. Chem. Commun. 2016, 52, 5418-5420. [CrossRef]

32. Sánchez-González, J.; Peña-Gallego, Á.; Sanmartín, J.; Bermejo, A.M.; Bermejo-Barrera, P.; Moreda-Piñeiro, A. NMR spectroscopy for assessing cocaine-functional monomer interactions when preparing molecularly imprinted polymers. Microchem. J. 2019, 147, 813-817. [CrossRef]

33. Sander, J.; Janzen, N.; Terhardt, M.; Sander, S.; Gökcay, G.; Demirkol, M.; Ozer, I.; Peter, M.; Das, A.M. Monitoring tyrosinaemia type I: Blood spot test for nitisinone (NTBC). Clin. Chim. Acta 2011, 412, 134-138. [CrossRef] [PubMed] 
34. La Marca, G.; Malvagia, S.; Materazzi, S.; Della Bona, M.L.; Boenzi, S.; Martinelli, D.; Dionisi-Vici, C. Erratum: LC-MS/MS method for simultaneous determination on a dried blood spot of multiple analytes relevant for treatment monitoring in patients with tyrosinemia type I. Anal. Chem. 2014, 86, 10501. [CrossRef]

35. Zakaria, R.; Allen, K.J.; Koplin, J.J.; Roche, P.; Greaves, R.F. In this issue: Recent developments in the clinical application of mass spectrometry Advantages and challenges of dried blood spot analysis by mass spectrometry across the total testing process. Ejifcc 2016, 27, 288-317.

36. Laeremans, H.; Turner, C.; Andersson, T.; Angel Cocho De Juan, J.; Gerrard, A.; Rebecca Heiner-Fokkema, M.; Herebian, D.; Janzen, N.; La Marca, G.; Rudebeck, M. Inter-laboratory analytical improvement of succinylacetone and nitisinone quantification from dried blood spot samples. JIMD Rep. 2020, 53, 90-102. [CrossRef]

37. Korytkowska-Wałach, A.; Dubrawska, B.; Śmiga-Matuszowicz, M.; Bieg, T. Spectroscopic study on the inclusion complexes of $\beta$-cyclodextrin with selected metabolites of catecholamines. J. Mol. Struct. 2017, 1127, 532-538. [CrossRef]

38. Hynes, M.J. EQNMR: A computer program for the calculation of stability constants from nuclear magnetic resonance chemical shift data. J. Chem. Soc. Dalton Trans. 1993, 2, 311-312. [CrossRef]

39. Liu, Y.Y.; Fan, X.D. Synthesis and characterization of pH- and temperature-sensitive hydrogel of N-isopropylacrylamide/cyclodextrin based copolymer. Polymer 2002, 43, 4997-5003. [CrossRef]

40. Korytkowska-Wałach, A.; Śmiga-Matuszowicz, M.; Waśkiewicz, S.; Pietrzak, K. Patent pending [WIPO ST 10/C PL4311S5]. 2019.

41. Liu, L.; Meng, Y.; Volinsky, A.A.; Zhang, H.J.; Wang, L.N. Influences of albumin on in vitro corrosion of pure Zn in artificial plasma. Corros. Sci. 2019, 153, 341-356. [CrossRef]

42. PubChem. Available online: https://pubchem.ncbi.nlm.nih.gov/compound/Nitisinone (accessed on 18 August 2021).

43. Gottlieb, H.E.; Kotlyar, V.; Nudelman, A. NMR Chemicals Shifts of common laboratory solvents as traces imputities. J. Org. Chem. 1997, 62, 7512-7515. [CrossRef] [PubMed]

44. Choi, S.H.; Hwang, Y.M.; Ryoo, J.J.; Lee, K.P.; Ohta, K.; Takeuchi, T.; Jin, J.Y.; Fujimoto, C. Surface grafting of glycidyl methacrylate on silica gel and polyethylene beads. Electrophoresis 2003, 24, 3181-3186. [CrossRef]

45. Sebestyén, Z.; Buvári-Barcza, Á.; Rohonczy, J. pH-dependent complex formation of amino acids with $\beta$-cyclodextrin and quaternary ammonium $\beta$-cyclodextrin. J. Incl. Phenom. Macrocycl. Chem. 2012, 73, 199-210. [CrossRef]

46. Shanmugam, M.; Ramesh, D.; Nagalakshmi, V.; Kavitha, R.; Rajamohan, R.; Stalin, T. Host-guest interaction of L-tyrosine with $\beta$-cyclodextrin. Spectrochim. Acta Part A Mol. Biomol. Spectrosc. 2008, 71, 125-132. [CrossRef] 